\title{
Bertrand Thierry de Crussol des Epesse. La psychiatrie médiévale persane. La maladie mentale dans la tradition médicale persane
}

Fabrizio Speziale

\section{(2) OpenEdition}

Journals

Édition électronique

URL : http://journals.openedition.org/abstractairanica/40727

DOI : 10.4000/abstractairanica.40727

ISSN : 1961-960X

Éditeur :

CNRS (UMR 7528 Mondes iraniens et indiens), Éditions de l'IFRI

Édition imprimée

Date de publication : 1 décembre 2013

ISSN : 0240-8910

Référence électronique

Fabrizio Speziale, «Bertrand Thierry de Crussol des Epesse. La psychiatrie médiévale persane. La maladie mentale dans la tradition médicale persane », Abstracta Iranica [En ligne], Volume 32-33 | 2013, document 2010, mis en ligne le 01 juillet 2016, consulté le 26 septembre 2020. URL : http:// journals.openedition.org/abstractairanica/40727 ; DOI : https://doi.org/10.4000/abstractairanica. 40727

Ce document a été généré automatiquement le 26 septembre 2020.

Tous droits réservés 


\title{
Bertrand
}

\section{Thierry de Crussol des Epesse. La psychiatrie médiévale persane. La maladie mentale dans la tradition médicale persane}

\author{
Fabrizio Speziale
}

\section{RÉFÉRENCE}

Bertrand Thierry de Crussol des Epesse. La psychiatrie médiévale persane. La maladie mentale dans la tradition médicale persane. Paris, Springer, 2010, p. 208. (Médecins d'Asie Savoirs et pratiques)

Cet ouvrage de Thierry de Crussol des Epesse explore magistralement l'univers de la maladie mentale dans le monde persan et dans sa culture médicale notamment. L'analyse présentée se base principalement sur l'étude des chapitres correspondants de la DaHî̀ra-yi Hु̛̃ārazmšāhī de 'Ismā’îl Jurjānī (m. 531/1137), l'une des plus importantes encyclopédies médicales persanes composées à l'époque médiévale. L'A. compte parmi les experts majeurs de ce classique de la littérature médicale persane, à lequel il a déjà consacré une étude traitant de la section sur l'ophtalmologie de la DaHîra (Discours sur l'œil d'Esmấil Gorgânî, Téhéran, 1998). La première partie de l'ouvrage de Thierry de Crussol des Epesse examine l'ensemble des doctrines physiologiques expliquant la composition et les fonctions de la sphère mentale, ici sont analysés les principes de la constitution somatique, la vision du pneuma (rūhn), les organes liés à la dimension mentale, c'est-à-dire le cœur et le cerveau, les sens externes et les sens internes, la fonction de l'intellect ('aql). La deuxième partie est consacrée à l'interprétation de la pathologie mentale et psychique. Cette partie offre un panorama détaillé de la 
nosographie psychiatrique employée par les médecins persans médiévaux. La troisième partie explore les approches thérapeutiques et la prise en charge des troubles mentales. Elle examine les croyances liées à la prévention de la maladie mentale et les différents remèdes employés par les médecins : les remèdes simples, les médicaments composés, les liniments, les cataplasmes, les lotions, les purges, la saigné, les venteuses, l'aromathérapie, la musicothérapie. Les derniers paragraphes examinent la gestion de la maladie mentale dans la société et le rôle des hôpitaux.

\section{AUTEURS}

\section{FABRIZIO SPEZIALE}

Université Sorbonne Nouvelle-Paris 3, Mondes iranien et indien, Paris 